\title{
Based on the statistical analysis of taijiquan culture heritage and development of colleges and universities
}

\author{
Yaodong Huang \\ Department of Physical Education, Guangdong University of Foreign Studies, Guangzhou 510006, China
}

\begin{abstract}
Now rank universities are actively carry out the physical education of Chinese traditional sports, including tai chi course is the most common, and colleges and universities are equipped with the corresponding physical education teachers to teach tai chi chuan, this for the development and popularization of taijiquan provides a good place to start. This article adopts the method of mathematical statistics analysis to tai chi course in common colleges and universities as the research object to study. As a result, the taijiquan movement cultures the present situation in China and its influence on college students. In ordinary colleges and universities in Beijing, although many colleges and universities opened a tai chi class movement of physical education, but, in the eyes of students did not get the attention, practiced tai chi and the number of people willing to practice tai chi chuan for a long time not many.
\end{abstract}

\section{Introduction}

Taijiquan is a Chinese traditional sports an important part of wushu and tai chi as the excellent traditional culture, gradually by the world more and more people understand and accept. And tai chi as the important content of Chinese martial arts curriculum by means of spreading Chinese traditional culture in colleges and universities is a good platform.

Now developed into the current situation of Chinese wushu, the reason is various, first of all, there are historical reasons, its development has experienced the "cultural revolution", etc. Some setbacks, followed by the Chinese wushu itself, some of the routines are for some special populations, not suitable for the people, finally, because most of the Chinese wushu routines lacks affect mostly just for show. Another reason is that Chinese wushu branches numerous, each faction, lack of unity and integration, yes some good projects buried among them, the forgotten over time. Although Chinese martial arts have the disadvantages of the above, but there are many of his merit.

Taijiquan as a form of Chinese martial arts, it is China's outstanding cultural heritage, in the world within the scope of influence is also gradually expanded, as the birthplace of tai chi chuan, China has a good mass base, this is tai chi to inheriting the basic conditions in China. Along with the popularization of higher education in China, high quality talent doubling every year, the popularity of tai chi group also had significant changes, the development of tai chi chuan is indispensable to learn tai chi chuan population quality, it as a high quality of Chinese traditional sports, a man of high quality dry level as its propaganda, tai chi will be accepted by more and more people in the future. Chinese martial arts it can nourish, prosperity, and long long, showing the value of its existence. Chinese martial arts development up to now, there are a lot of be separated, deep love of the people throughout the country, at present, the development of the Chinese martial arts is the international community, also gradually accepted by the world, shows the strong force of the development of it.

\section{Model establishments}

To Taijiquan cultural inheritance and influences, here mainly carries out questionnaire survey on Beijing ordinary colleges. Here, it makes data statistical analysis of Beijing ordinary colleges Taijiquan teaching status, Beijing ordinary colleges Taijiquan teaching faculty status, Taijiquan course reforming, students' impetus these aspects.

\subsection{Ordinary colleges Taijiquan teaching status}

According to current Beijing ordinary colleges relative Chinese traditional sports syllabus arrangement, all universities in Beijing have formulate teaching plans according to their own status, set up physical courses that conform to their own school practice to meet university students' requests on sports culture. Here make statistics of Beijing universities sports courses with Taijiquan arrangement, statistical result is as Figure 1. (Data specification: " 1 " represents the event already set up, "0" represents that it hasn't yet set up the event)

a Corresponding author: YaodongHuang@163.com 


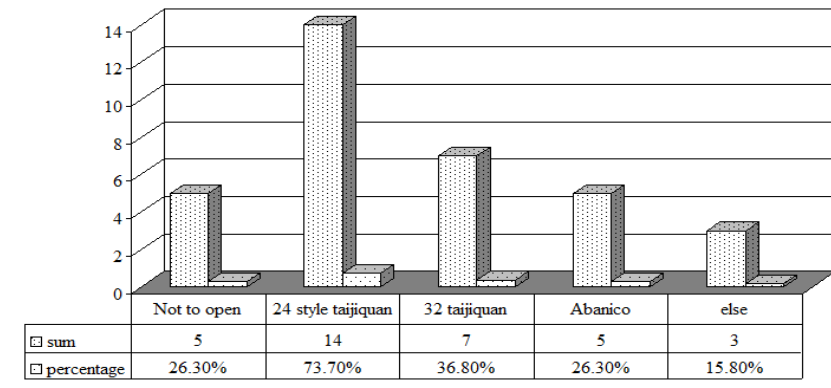

Figure 1. Tai chi are scheduled for Beijing college physical education.

By above analysis, it is clear that most of Beijing ordinary colleges set up sports course regarding Taijiquan, from which investigated universities have 14 universities set up " 24 style Taijiquan" that occupy $73.70 \%$ of total proportions, and seven universities set up "32 style Taijiquan" that occupy $36.80 \%$ of total proportions, five universities set up "abanico" that occupy $26.3 \%$ of total proportions, three universities set up other sports courses related to Taijiquan movements that occupy $15.80 \%$ of total proportions, only five universities haven't set up Taijiquan relative sports course that occupies $26.30 \%$ of totals.

To universities that set up relative Taijiquan movements, make analysis of their teachers' status.

\subsection{Universities Taijiquan teachers status}

Firstly, make statistics and sort out Taijiquan teachers and sports teachers from each university of Beijing. By above analysis, it is clear that in each university of Beijing, first-tier institution, second-tier institution, third-tier institution and junior college sports teachers' amounts are in the declining trend, for third-tier institution and junior college sports teachers, either no one or just Taijiquan teachers.

Then analyze Beijing ordinary colleges' martial arts major teachers' proportions, the results are as Figure 2. (Data source: $\mathrm{Wu} \mathrm{Ma}$ and others questionnaire survey results.)

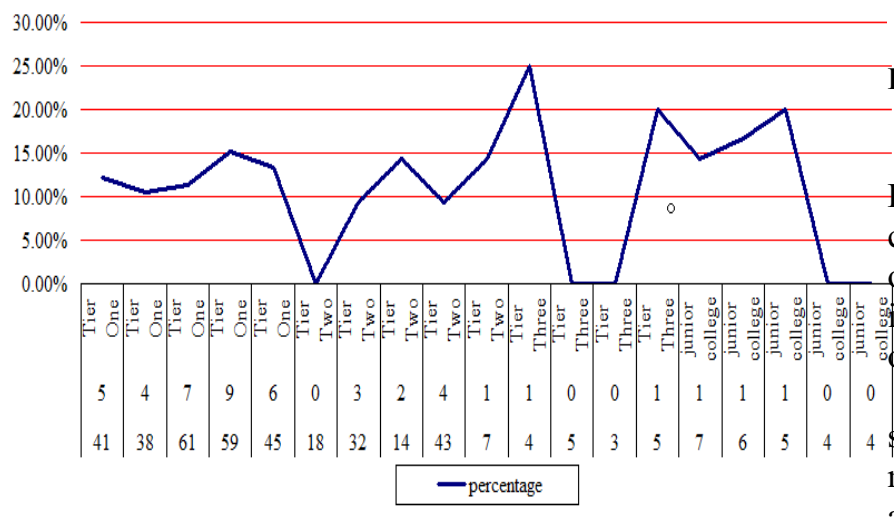

Figure 2. The share of martial arts teachers in physical education teacher.

Correspond to above analysis; it is clear that martial arts major teachers proportion in Beijing universities sports teachers are in fluctuation state.
Finally, make investigation on universities students to see whether students know their schools' Taijiquan courses are taught by professional martial arts teachers. Statistical results are as Table 1.

Table 1. University Taijiquan is taught by professional martial arts teachers.

\begin{tabular}{|c|c|c|c|c|c|}
\hline & $\begin{array}{c}\text { Not } \\
\text { filled }\end{array}$ & Yes & No & $\begin{array}{c}\text { Don't } \\
\text { know }\end{array}$ & $\begin{array}{c}\text { Total } \\
\text { number of } \\
\text { people }\end{array}$ \\
\hline $\begin{array}{c}\text { Number } \\
\text { of } \\
\text { people }\end{array}$ & 112 & 177 & 65 & 114 & 468 \\
\hline $\begin{array}{c}\text { Percent } \\
\text { age }\end{array}$ & $23.90 \%$ & $37.80 \%$ & $13.90 \%$ & $24.30 \%$ & $100.00 \%$ \\
\hline
\end{tabular}

(Data source: $\mathrm{Wu} \mathrm{Ma}$ and others questionnaire survey results.)

From above analysis, it can get that Beijing ordinary colleges students emphasis on their school Taijiquan course lectured by professional martial arts is not so high, only roughly $38 \%$ people know the status, $24 \%$ people don't fill in, and $14 \%$ people response that no sports course of martial arts teacher lecturing.

\subsection{University Taijiquan courses arrangement}

For Beijing ordinary colleges Taijiquan courses arrangement, it mainly investigates on universities sudents'Taijiquan study hour and Taijiquan theory course attendance status here. Here, one study hour course is 45 minutes; one course is two study hours. According to above investigation result, draw "black - white pie chart" as Figure 3.

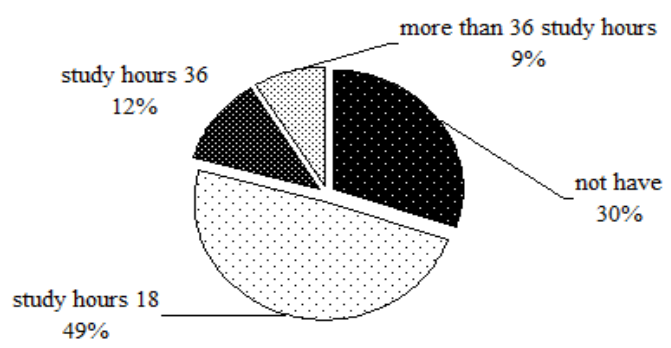

Figure 3. Ordinary college students' taijiquan class survey.

Correspond to above data analysis, it is clear that Beijing ordinary colleges' starting Taijiquan sports course's study hours concentrate on 18 study hours that occupy $49 \%$ of totals, it gets closer to a half, $30 \%$ institutions haven't started relative Taijiquan sports course, only $12 \%$ is 36 study hours, $9 \%$ is above 36 study hours.

Then make investigation on universities Taijiquan setup theory course, Here, one study hour course is 45 minutes; one course is two study hours. According to above investigation result, draw "black - white pie chart" as Figure 4. 


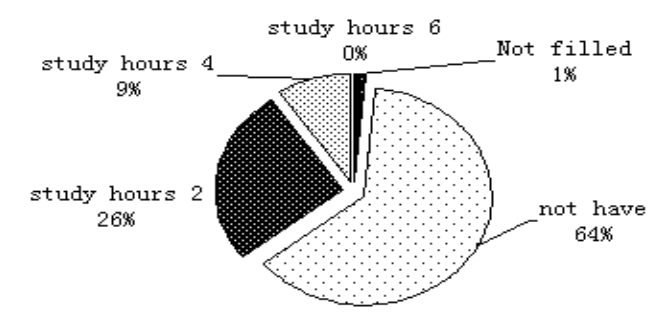

Figure 4. Ordinary colleges and universities offer taiji theory.

From above analysis, it is clear that most of Beijing ordinary colleges haven't set up Taijiquan theory course that is $64 \%$ of totals, even for school that set up Taijiquan theory course that still not goes beyond 6 study hours.

\section{Ordinary colleges' Taijiquan development influential factors}

According to present Beijing ordinary colleges' relative Chinese traditional sports syllabus arrangement, all universities in Beijing formulate teaching plans according to their own status, set up physical courses that conform to their own school practice to meet university students' requests on sports culture. Here, analyze Beijing universities sports course with Taijiquan arrangement development factors, firstly make statistics of influence factors status that supposed by teachers and students, as Table 2.

Table 2. Taijiquan course quality influence factors.

\begin{tabular}{|c|c|c|c|c|}
\hline $\begin{array}{c}\text { Influence } \\
\text { factors }\end{array}$ & Teacher & $\begin{array}{c}\text { Percenta } \\
\text { ge }\end{array}$ & Student & $\begin{array}{c}\text { Percenta } \\
\text { ge }\end{array}$ \\
\hline $\begin{array}{c}\text { Do not take the } \\
\text { leadership }\end{array}$ & 3 & $1.50 \%$ & 35 & $7.50 \%$ \\
\hline Little lesson & 16 & $80 \%$ & 111 & $23.70 \%$ \\
\hline $\begin{array}{c}\text { The teaching } \\
\text { content is boring }\end{array}$ & 7 & $35 \%$ & 348 & $74.40 \%$ \\
\hline $\begin{array}{c}\text { Students' } \\
\text { enthusiasm is } \\
\text { not high }\end{array}$ & 16 & $80 \%$ & 287 & $61.30 \%$ \\
\hline $\begin{array}{c}\text { Teachers' } \\
\text { enthusiasm is } \\
\text { not high }\end{array}$ & 0 & $0 \%$ & 158 & $33.80 \%$ \\
\hline $\begin{array}{c}\text { Teachers' own } \\
\text { technical } \\
\text { limitations }\end{array}$ & 0 & $0 \%$ & 71 & $15.20 \%$ \\
\hline Else & 6 & $30 \%$ & 119 & $25.40 \%$ \\
\hline Unfilled & 0 & $0 \%$ & 29 & $6.20 \%$ \\
\hline $\begin{array}{c}\text { Total number } \\
\text { of people }\end{array}$ & 20 & & 468 & \\
\hline
\end{tabular}

(Data source: $\mathrm{Wu} \mathrm{Ma}$ and others questionnaire survey results.)

From above analysis, it is clear that Beijing ordinary colleges teachers think that Taijiquan course quality influence factors are mainly as little lesson, students' enthusiasm is not high, while for students, they think that causes of Taijiquan course quality main influential factors mainly are teaching content is boring, little lesson and teachers' enthusiasm is not high .

\subsection{Students' Taijiquan exercises impetus analysis}

For Taijiquan cultural inheritance and influences, it mainly makes questionnaire survey on Beijing ordinary colleges here. Here makes data statistical analysis of Beijing ordinary colleges students' impetus aspects, the results are as Table 3 .

Table 3. Ordinary colleges' students' Taijiquan learning impetus.

\begin{tabular}{|c|c|c|}
\hline & $\begin{array}{c}\text { Number } \\
\text { of people }\end{array}$ & Percentage \\
\hline Interesting & 41 & $8.80 \%$ \\
\hline Have a try & 77 & $16.50 \%$ \\
\hline Gather together credits & 318 & $67.90 \%$ \\
\hline Other causes & 32 & $6.80 \%$ \\
\hline Total number of people & 468 & $100.00 \%$ \\
\hline
\end{tabular}

(Data source: Wu Ma and others questionnaire survey results.)

From above analysis, it can get that main purpose of ordinary colleges' students learning Taijiquan is to gather together credits that occupy $68 \%$ of totals, and still $9 \%$ colleges students are because of interesting in Taijiquan. By above statistical result, it can analyze and get that in Beijing ordinary colleges, though many colleges set up Taijiquan type movement physical courses, it doesn't attract students' attentions, number of people that take Taijiquan exercises and willing to take Taijiquan exercises for a long time are not many.

\section{Conclusions}

In present stage, universities in Beijing are positive organizing relative Chinese traditional sports events physical education courses, from which Taijiquan course also has guarantee of syllabus in teaching aspects, it doesn't attract students' attentions, and number of people that take Taijiquan exercises and willing to take Taijiquan exercises for a long time are not many. Now, since advanced education introduces multiple-media teaching, teaching quality and efficiency are greatly improved, here it can also increase students' interests in Taijiquan type of movements by multiple-media video broadcasting excellent Taijiquan type of movements, let people to directly understand Taijiquan movement essence, let students' to find pleasure in it and love Taijiquan rather than let them to be bored and mechanically simulate.

\section{Acknowledgment}

This research was supproted by 2015 Guangdong Province Disciplinary Construction Project during the 12th Five-Year Plan Period for Philosophy and Social Science. Project Number: GD15XTY07.

\section{References}

1. YE Xiang-wen, Bulletin of Sport Science \& Technology, 19, 112-113, 125(2011). 
2. WANG Gang, Journal of Capital College of Physical Education, 20, 1-4(2008).

3. HU Yonggang, Journal of Shenyang Sport University, 28, 110-113, 128(2009).

4. Li Rongzhi, Yu Chonggan, Sports Culture Guide, 4, 84-86(2007).
5. Huang Hui, Liu Zhenling, International Conference On Engineering And Business Management, 1-8, 5186-5189(2010).

6. Xu F, Lu H, Ding N, et al. Journal of Coastal Research, 73, 635-640(2015). 